\title{
Using Health-Saving Technologies in Kindergarten
}

\author{
D Sharipova $^{1}$ and V Abduazizova ${ }^{2 *}$ \\ ${ }^{1}$ Tashkent State Pedagogical University, Uzbekistan \\ ${ }^{2}$ Namangan Engineering Construction Institute, Uzbekistan \\ *Corresponding author: V Abduazizova, Namangan Engineering Construction Institute, Uzbekistan
}

\begin{tabular}{lll}
\hline ARTICLE INFO & ABSTRACT \\
\cline { 1 - 1 } Received: 幽 June 25, 2020 & $\begin{array}{l}\text { This article has developed systems of health-saving activities of educators } \\
\text { and parents that create the maximum possible conditions for the preservation, } \\
\text { strengthening and development of spiritual, emotional, intellectual, personal and } \\
\text { physical health of children. }\end{array}$ \\
\hline
\end{tabular}

Citation: D Sharipova, V Abduazizova. Using Health-Saving Technologies in Kindergarten. Biomed J Sci \& Tech Res 28(4)-2020. BJSTR. MS.ID.004687.
Keywords: Family; Kindergarten; Health; Health-Saving Technologies; Children's Health Promotion

\section{Introduction}

Family and kindergarten-this is the microclimate in which a child of preschool age lives. This is the environment in which he acquires the necessary information and adapts to life in society. However, parents do not have sufficient knowledge of the age and individual characteristics of the child's development. Family and kindergarten are two public institutions that stand at the origins of our future, but they often do not always have enough understanding, tact, and patience to hear and understand each other. To form a position of cooperation between teachers and children and their parents, it is necessary to create a unified space for child development, which should be supported by both the kindergarten and the family [1]. In order to build effective communication between teachers and parents, it is important to have communicative skills, navigate the problems of education and the needs of the family, and be aware of the latest scientific achievements.

In the process of organizing a unified health-saving space KINDERGARTEN and family you can use various forms: open sessions with the children for parents; pedagogical conversations with parents-General parent group meeting; consultations; classes with parents; exhibitions of children's works, made together with parents; open Days; participation in preparation and carrying out of holidays, leisure; joint creation of subject-developing environment; work with the parent Committee groups; trainings; parent Seating, questionnaire. Colorful visual stands in reception rooms introduce parents to the life of the group, with the age characteristics of children. In the corners of specialists there is information of a practical orientation, interesting facts are given, recommendations of a teacher-psychologist, physical education and music workers are given.

Family and kindergarten-this is the microclimate in which a child of preschool age lives. This is the environment in which he draws the necessary information and adapts to life in society.

The concept of preschool education emphasizes: "the Family and kindergarten are chronologically linked by a form of continuity, which facilitates the continuity of education and training of children. However, the preschooler is not a baton that the family passes on to the teacher. What is important here is not the principle of parallelism, but the principle of interpenetration. The most important condition for continuity is the establishment of a trusting business contact between the family and the kindergarten, during which the educational position of parents and teachers is adjusted."

The goal and tasks facing the family and kindergarten should be the same-to provide the child with the most favorable healthsaving conditions for development, which are characterized by psychological and pedagogical conditions of education and training, content and methods, the nature of interaction between teachers and children and the formation of a child's moral attitude to their health, which is expressed in the desire and need to be healthy, lead a healthy lifestyle. 
Taking into account all the factors of formation of the child's body, individual characteristics of children, the following tasks are defined in the sphere of protection and promotion of children's health, both in kindergarten and in working with parents:

Tasks for kindergarten:

1. Protect and promote children's health,

2. Improve their physical development,

3. Improve physical and mental performance,

4. Educate children and parents in the need for a healthy lifestyle,

5. Develop basic physical abilities and the ability to use them efficiently in various conditions,

6. Promote the assimilation of rules of hygiene and culture of life. Tasks in working with parents:

7. Provide concrete practical assistance to the family in creating conditions for preserving and strengthening the child's health,

8. To attract parents to the implementation of the educational process, creating a healthy environment,

9. Take into account the wishes of parents when drawing up individual work programs.

\section{Literature Review}

Traditional forms of organizing work with parents to develop healthy lifestyle skills in preschool children are physical recreation and sports events with the participation of parents and preschool employees, consultations, and conversations. But the problem is that parents often act as spectators and less often as participants in sports events. Today, when parents often experience difficulties in communicating with their own child, we can not limit ourselves to the promotion of pedagogical knowledge, in which parents are only passive participants. The effectiveness of work is provided by such forms of work in which knowledge is presented in the process of cooperation between the teacher and parents, active interaction between an adult and a child. One of these forms is joint physical exercises of parents and children. They help parents acquire not only theoretical knowledge, but also practical skills in the field of physical education of children. And in the case of participation of the teacher, the head of physical education and parents, family relations between children and parents are consolidated. In the process of organizing a unified health-saving space on the basis of our preschool educational institution, we use various forms of work: open classes in valeology with elements of health-saving technologies under the guidance of A. Sh.Nafikova. Pedagogical conversations with parents - General and group parent meetings held by 0 . V. Grigorieva. educational activities short-term project "Watchful eyes", exhibitions of children's works made together with parents, participation of parents in the preparation and conduct of holidays, leisure, training, one of the most effective methods in this direction- the use of visual agitation, each group has a health corner, where all information for parents about medical treatment is placed - there is a "piggy Bank of health" in which all the material about non-traditional methods of health improvement, material promoting a healthy lifestyle is collected. Open days are regularly organized for parents.in our opinion, this is an effective form of involving family members in the educational process.

\section{Methodology}

The staff of the preschool educational institution is mobilized to implement measures that help to achieve certain goals in reducing the incidence of diseases. Extensive preventive work with children, parents, employees, of course, has certain positive results. The goal of health-saving technology is to provide preschool children with a high level of real health, arming them with the necessary knowledge, skills, and skills necessary for maintaining a healthy lifestyle, and educating them with a culture of health. Many tasks that the teacher solves in the course of his activity are subordinated to the solution of this goal. Teachers in kindergartens teach children the culture of health, how to take care of their bodies, that is, a conscious attitude to their health, safe behavior.

\section{Challenges of health-saving technology:}

1. Combine the efforts of employees and parents for effective organization of physical culture and health work, including prevention of violations of flat feet and posture.

2. Teach children safe behavior in emergency situations in nature and the metropolis.

3. To carry out continuity between preschool educational institution and school by means of physical culture and healthimproving work.

The main health-saving technologies used in the educational activities of pre-SCHOOL institutions include:

\section{Technologies for Preserving and Stimulating the Health of Preschool Children Include:}

Stretching: No earlier than 30 minutes after eating, 2 times a week for 30 minutes. from middle age, special exercises to music in gyms or music halls, or in a group room, in a well-ventilated room. Recommended for children with sluggish posture and flat feet.

Dynamic Pauses: During classes, 2-5 min., as children become tired. Recommended for all children as a prevention of fatigue. They may include elements of eye gymnastics, breathing exercises, and others, depending on the type of activity.

Mobile and Sports Games: As part of a physical education class, on a walk, in a group room-small, medium and high mobility Daily for all age groups. Games are selected according to the age of the child, the place and time of its holding. In kindergarten, we only use elements of sports games. 
Relaxation: In any suitable room, depending on the children's condition and goals, the teacher determines the intensity of the technology. For all age groups. You can use quiet classical music (Tchaikovsky, Rachmaninoff), sounds of nature. A special relaxation room has been created in our kindergarten.

Finger Gymnastics: From a young age individually or with a subgroup daily. Recommended for all children, especially those with speech problems. It is held at any convenient time (at any convenient time).

Eye Gymnastics: Every day for 3-5 minutes. in any free time, depending on the intensity of visual load from a young age. It is recommended to use visual material, showing the teacher.

Respiratory Gymnastics: In various forms of physical culture and health work. Provide ventilation of the room, the teacher should give instructions to children about mandatory hygiene of the nasal cavity before the procedure.

Corrective Gymnastics: in various forms of physical culture and health work. The form of the event depends on the task and the number of children.

Orthopedic Gymnastics: In various forms of physical culture and health work. It is recommended for children with flat feet and as a prevention of diseases of the supporting arch of the foot [2].

\section{Technologies for Teaching A Healthy Lifestyle:}

Physical education classes: 2-3 times a week in sports or music halls. Early age - in a group room, 10 min. Younger age-1520 min., middle age-20-25 min., older age-25-30 min. Before the lesson, it is necessary to ventilate the room well.

Problem-Game Training (Agrotrading and Game-Based Rehabilitation): In free time in the afternoon. Time is not strictly fixed, depending on the tasks set by the teacher. The lesson can be organized not noticeably for the child, by including the teacher in the process of playing activities.

Communication Games: 1-2 times a week for 30 minutes. from an older age. Classes are built according to a certain scheme and consist of several parts. They include conversations, studies and games of varying degrees of mobility, drawing, modeling, etc.

\section{Corrective Technologies:}

Technologies of Musical Influence: In various forms of physical culture and health work; or separate classes 2-4 times a month, depending on the goals set. They are used as an auxiliary tool as part of other technologies; to relieve tension, increase emotional mood, etc.

Skazkoterapiya: 2-4 classes per month for $30 \mathrm{~min}$. from an older age. Classes are used for psychological therapeutic and developmental work. A fairy tale can be told by an adult, or it can be a group storytelling, where the narrator is not one person, but a group of children, and the other children repeat the necessary movements after the narrators.

Color Exposure Technologies: Correctly selected interior colors in our group relieve stress and increase the emotional mood of the child.

The health-saving technologies used in the complex eventually form a strong motivation for a healthy lifestyle in the child.

To make children want to engage, it is important to interest the child from the first minute. To do this, you must first think through the methodological techniques that will help you solve the tasks. In conclusion, we note that the main caregivers of the child are the parents. The child's future depends on how well the child's daily routine is organized and how much attention parents pay to the child's health.

\section{Results}

To bring up a healthy younger generation, it is necessary to: provide a flexible health regime; monitor the dynamics of development of pupils; conduct corrective work; work with parents; use health technologies [3].

The last condition is very important as there must be a continuity of the kindergarten and the family. Implementation of this condition can take place through such forms and methods of work as tips and recommendations:

a. Observe the daily routine, i.e. rationally allocate time for sleeping, eating, and various activities,

b. Organize special hardening procedures at home: washing, gymnastics, dousing or wiping,

c. Teach children to the wind, cold, burning sun, all the dangers that should be despised, thereby hardening their body,

d. Do not cover up children (clothing for walking should be warm, but not restrict the movement of the child),

e. Monitor the children's posture: while walking, the child should walk without lowering his head, with his shoulders unfolded,

f. Buy children skis, sleds, skates, balls, hoops, skittles,

g. Pay special attention to shoes when walking,

h. Use indirect effects on the child, to play, to read poems, nursery rhymes, pestushko, read books,

i. To develop children's skills of safe behavior for life and health,

j. Use greeting, farewell, and gratitude formulas in communication with children in accordance with the rules of etiquette, 
k. To raise children's sense of duty, responsibility, and humanity,

l. Observe the principles of equality and cooperation with children,

m. Remember that parents who are neglectful of their health cannot form the right attitude to the health of their child.

Having a health-improving orientation, the health-saving activity used in the complex will eventually form a stable motivation for a healthy lifestyle and full-fledged development in the child [4].

Thus, in the process of organizing health-saving activities in kindergarten, it is important to create emotionally comfortable

ISSN: 2574-1241

DOI: $10.26717 /$ BJSTR.2020.28.004687

V Abduazizova. Biomed J Sci \& Tech Res

(c) (i) This work is licensed under Creative

Submission Link: https://biomedres.us/submit-manuscript.php conditions for the child to stay in it and to promote his physical, spiritual and social well-being.

\section{References}

1. Akhutina TV (2000) Health-Saving technologies of training: an individual-oriented approach. School of health 7: 2.

2. Chubarova S, Kozlovskaya G, Eremeeva V (2005) New health saving technologies in education and upbringing of children. Personal development pp. 171-187.

3. Gavryuchina LV (2007) health-Saving technologies in DOW: a Methodological guide. -M: shopping center "SFE-RA" pp. 160.

4. Astafiev NS (2012) Planning activities with children in all educational areas. - Moscow: center for additional education "Ascension", Moscow, p. 72.

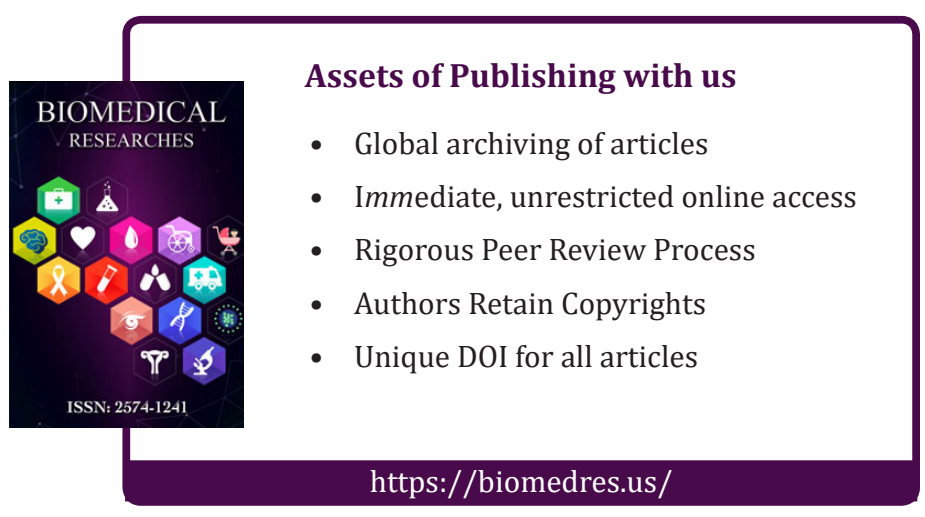

